\title{
«NAVEGANDO EN LA OSCURIDAD»: IRIS MURDOCH Y LA ENFERMEDAD DE ALZHEIMER
}

\author{
«SAILING AWAY INTO THE DARKNESS» \\ IRIS MURDOCH AND ALZHEIMER'S DISEASE
}

Mariángel SOLÁNS GARCÍA

\author{
Universidad Nacional de Educación a Distancia \\ masolans@madrid.uned.es
}

\begin{abstract}
Resumen: El aumento de la esperanza de vida y de la población anciana ha derivado en una alta incidencia de la enfermedad de Alzheimer (EA). El objetivo del presente artículo es reflexionar sobre la interdisciplinaridad del estudio de la EA, cuyo interés ha traspasado del ámbito biomédico a otras disciplinas, como la literatura. Nos centraremos en el caso de la escritora británica Iris Murdoch como enferma de Alzheimer. Así mismo resaltamos el valor de la narrativa en la representación y en el análisis de la enfermedad. Para concluir, nos centraremos en el tema de la memoria en los textos de la escritora.
\end{abstract}

Abstract: The increase in life expectancy and in elderly population has resulted in a high incidence of Alzheimer's disease (AD). The aim of this article is to discuss the interdisciplinarity of the study of $\mathrm{AD}$, as it has crossed boundaries from the biomedical science to include other fields, such 
as literature. We will refer to the British writer Iris Murdoch as an Alzheimer's patient. In addition, we will highlight the value of narrative in the representation and analysis of the disease. To conclude, we will focus on the question of memory and loss in the texts of this writer.

Palabras clave: Enfermedad de Alzheimer. Demencia. Narrativa. Memoria. Literatura. Iris Murdoch.

Key words: Alzheimer's disease. Dementia. Narrative. Memory. Literature. Iris Murdoch.

\section{IRIS MURDOCH: ASPECTOS BIOGRÁFICOS}

Iris Murdoch es considerada una de las escritoras en lengua inglesa más influyentes y productivas del siglo XX, así como una gran filósofa, destacando principalmente por sus reflexiones en el campo de la moral. Sin embargo, aunque recibió el doctorado honoris causa por la Universidad de Alcalá de Henares en 1993, es una autora poco conocida para el púbico español. Se hace necesaria, por tanto, una breve presentación sobre ella.

Nació en Dublín en 1919, pero pasó la mayor parte de su vida en Inglaterra. Hija única de padres anglo-irlandeses, tan solo resalta de su infancia que fue tranquila y feliz. Como muchos otros intelectuales, militó en el Partido Comunista en los años treinta, aunque lo abandonó desilusionada, manteniendo siempre una postura política cercana a la izquierda. Esta corta afiliación le impediría más adelante disfrutar de una beca de estudios en EE.UU. al serle denegado el visado por esta causa.

Durante la Segunda Guerra Mundial trabajó en un comité de las Naciones Unidas en Reino Unido, Bélgica y Austria, participando en programas de ayuda a los refugiados. Lo que más le impresionó fue la tristeza de los ancianos desplazados de sus países de origen. En Bruselas entró en contacto con el existencialismo francés, siendo una de las primeras lectoras de la obra de Jean Paul Sartre. Igualmente importante es el influjo que ejerció en ella la filósofa francesa Simone Weil, también próxima a los círculos existencialistas: su obra fue leída y profundamente meditada por la autora y su huella se rastrea fácilmente en algunas de sus novelas.

Aunque afirmaba que su labor como filósofa no interfería en su actividad literaria, es indudable que ambos campos se entrecruzan, de forma que sus novelas plantean frecuentemente preguntas acerca de quiénes somos y qué mundo habitamos. Todos estos temas afloran de una u otra manera en 
sus novelas, de contenido profundo, más ricas y complicadas de lo que pueden parecer a primera vista, permitiendo múltiples interpretaciones.

En los años setenta, consiguió el máximo reconocimiento del público y de la crítica, siendo galardonada con diversos premios, entre los que destaca el premio Booker-McConnel, el más prestigioso galardón de la crítica literaria inglesa, por su obra The Sea The Sea (1978). En 1987, fue nombrada Dama Comandante de la Orden del Imperio Británico.

Iris Murdoch trabajó como profesora en las universidades de Cambridge, Oxford y Londres. Aunque dejó su dedicación a la enseñanza en sus últimos años, no perdió el contacto con la vida académica, participando en conferencias, colaborando con diversas publicaciones y participando en la escena intelectual británica a un nivel inusual hoy en día entre los escritores (Todd, 1984: 19) hasta que su salud se lo impidió.

Aunque su primera novela vio la luz cuando ya tenía 35 años, fue una escritora prolífica. Escribió veinticinco novelas, algunas de las cuales fueron llevadas al teatro, seis obras filosóficas y dos volúmenes de poesía. Se casó con el crítico literario, profesor y novelista John Bayley cuando este ejercía como profesor en la universidad de Oxford. Estuvieron casados durante 40 años.

Como Conradi (2010: 429) expone en sus memorias, Iris Murdoch disfrutaba escribiendo, constituyendo su rutina diaria hasta que su enfermedad se lo impidió. Entre el final de una novela y el inicio de otra, podía trascurrir no más de media hora, ya que no podía imaginar la vida sin una novela en marcha. Era una mujer vitalista, brillante y sin prejuicios. Viajó por todo el mundo: Egipto, Israel, Australia, Nueva Zelanda, China, India, Japón, Corea, Islandia, Singapur, Rusia y por supuesto Europa, pues, en su afán por aprender, se interesó por conocer otras culturas, mostrándose especialmente atraída por India, Japón y Rusia, e incluso estudió otras lenguas para entenderlas mejor. Aprendió francés, latín y griego y más tarde algo de alemán y ruso. En sus obras podemos encontrar citas en todos estos idiomas. Además, sabía escribir en esperanto e incluso trató de aprender turco.

En 1995 durante una entrevista en Israel, Iris Murdoch sufrió un episodio de amnesia y no fue capaz de encontrar las palabras para expresarse. Sus amigos comenzaron a percibir errores llamativos, como dificultades para entender algunas preguntas o problemas de memoria, olvidando cosas que habían hecho juntos. Estos trastornos constituyeron un signo de alarma, por lo que un equipo de neurólogos del Addenbrookes Hospital de Cambridge la 
sometió a una serie de exámenes y exploraciones neurológicas, contando en todo momento con su colaboración. A los 76 años recibió el duro golpe que cambió su vida: padecía la enfermedad de Alzheimer. Los exámenes neuropsicológicos mostraron una pérdida de sus habilidades cognitivas y las técnicas de neuroimagen mostraban cómo había encogido el hipocampo, la parte del cerebro que se encarga de la formación, organización y almacenamiento de la memoria. Tras el posterior análisis biológico del tejido cerebral, se detectó la presencia de placas y ovillos neurofibrilares, especialmente en el lóbulo temporal, el que controla los significados y la organización léxica de las palabras. Como ocurre en estos casos, el diagnóstico certero de la enfermedad solo pudo evidenciarse tras la muerte de la escritora, que contribuyó a la investigación médica donando su cerebro a la ciencia.

Falleció a los 79 años, el 8 de febrero de 1999, tras pasar tres semanas ingresada en Vale House (Oxford), un centro de cuidados paliativos para personas con demencia.

\section{IRIS MURDOCH Y LA ENFERMEDAD DE ALZHEIMER}

Las enfermedades neurodegenerativas relacionadas con la edad avanzada, y especialmente la enfermedad de Alzheimer (siglas EA), constituyen uno de los principales retos de este siglo, tanto médicos como sociales, políticos y económicos, a los que se enfrenta la sociedad actual. La enfermedad de Alzheimer es un trastorno neurológico irreversible y progresivo que resulta en el deterioro de ciertas partes del cerebro, causado por la acumulación de proteína beta-amiloide. Ello provoca que las neuronas pierdan capacidad para comunicarse entre ellas y que finalmente mueran. Se caracteriza por la aparición de síntomas relacionados con un deterioro cognitivo y trastornos de conducta, que evolucionan a lo largo de los años.

Hace ya más de 100 años que el neurólogo alemán Alois Alzheimer identificó por primera vez esta demencia en una mujer de 51 años. Este caso tan excepcional, hoy en día se ha convertido en una patología habitual dentro de las enfermedades neurodegenerativas. Un informe emitido en abril del 2012 por la Organización Mundial de la Salud (OMS) y la Asociación Internacional de Alzheimer (ADI), hacía una llamada a los gobiernos para hacer del Alzheimer y otras demencias una prioridad mundial de salud pública. Según datos actuales del Centro de Referencia Estatal (CRE) de Atención a Personas con Enfermedad de Alzheimer y otras Demencias, la enfermedad afecta a más de 25 millones de personas en todo el mundo, siendo la 
tercera causa de muerte por detrás de las enfermedades cardiovasculares y el cáncer. Dado el aumento de esperanza de vida, se prevé que la incidencia de afectados por la EA ascienda progresivamente, duplicándose cada 20 años a medida que la población vaya envejeciendo.

Si bien contamos con multitud de estudios que indican que esta compleja enfermedad provoca la muerte de las neuronas, no se conoce con exactitud su etiología ni los factores de riesgo que pueden desencadenarla, aunque se barajan diversas hipótesis. El tratamiento exitoso de la EA aún queda lejos, aunque empieza a haber investigaciones esperanzadoras, como el reciente diseño de la vacuna EB-101 por un equipo de científicos españoles que podría frenar el avance de la enfermedad en el futuro (Carrera et al., 2012).

Hoy en día está demostrada cierta predisposición genética para desarrollar la enfermedad, aunque se estima que solo un 5-10\% de las demencias de tipo Alzheimer parecen ser de tipo hereditario. Aunque la demencia de Iris Murdoch no perteneciera a esta modalidad, sabemos que contaba con antecedentes familiares, ya que su madre, Irene Murdoch, sufrió un fuerte deterioro mental en sus últimos diez años de vida, durante los cuales su hija ejerció el papel de cuidadora. Como señala Conradi (2010: 577), la enfermedad de su madre fue una experiencia muy dolorosa para la escritora, que, además, recayó sobre ella al ser hija única y haber muerto su padre. Debido a los episodios violentos que mostró Irene Murdoch en su etapa final, Iris Murdoch se vio obligada a ingresarla en varios centros para enfermos con demencias hasta su muerte en 1985.

Un estudio llevado a cabo por la Sociedad Radiológica de Norteamérica (RSNA, 2012) encontró diferencias de género en la evolución de la enfermedad, concluyendo que el deterioro de las células cerebrales es mayor y más temprano en la mujer, observándose en ellas una mayor atrofia en la sustancia gris doce meses antes de su diagnóstico. Por lo tanto, como en tantas otras patologías, la enfermedad de Alzheimer afecta de distinta manera a hombres y mujeres.

La enfermedad se empezó a reflejar en la última novela de Iris Murdoch, Jackson's Dilemma (1995), que llamó la atención por su brevedad y no gozó de buenas críticas. También Conradi, en su biografía de la autora (2010: 588), subraya la simplicidad de sus diarios personales correspondientes a esta época de su vida. Un doctor admirador de su obra, intrigado por el cambio de estilo de Jackson's Dilemma, encabezó un estudio que publicó la revista Brain (Garrard et al., 2005) en donde detectaba los primeros indicios de la enfermedad de Alzheimer. Tras escanear y estudiar los textos, estos evi- 
denciaron un vocabulario más escaso que en sus anteriores novelas, así como una sintaxis más sencilla. La propia escritora mostró serios problemas mientras trabajaba en la novela, pero los minimizó atribuyéndolos a un bloqueo creativo, un fenómeno psicológico en el que un escritor, normalmente en un momento de estrés, pierde la habilidad de escribir, la inspiración y la fluidez creativa, y que curiosamente había sufrido Bradley Pearson, protagonista de su novela The Black Princel (1973). En The Sacred and Profane Love Machine (1974) aparece un paciente de Blaise Gavender, Septimus Leech, un escritor con la inspiración «bloqueada» (Murdoch, 1974: 12) y que curiosamente también había aparecido en The Black Prince. La grafología de la escritora se fue alterando por la enfermedad, aunque siguió firmando ejemplares de sus obras con esmero y trabajosamente durante mucho tiempo (Bayley, 1999a: 37). Iris Murdoch se enorgullecía de escribir todas sus novelas a mano, hacía poco trabajo de revisión y enviaba sus manuscritos a sus editores, que se encargarían de su mecanografiado. Nunca consintió en usar un procesador de textos, ni tan siquiera tenía máquina de escribir, ya que no consideraba que fueran herramientas apropiadas para la escritura literaria.

Así como el personaje de Bradley Pearson sí logra salir de su bloqueo y encontrar la inspiración perdida y «felt those dark globules in the head, those tinglings in the fingers which token the advent of inspiration $»^{2}$ (Murdoch, 1973: 212), para Murdoch comenzaba su viaje hacia la oscuridad. Jackson's Dilemma sumió a la autora en una fuerte depresión al poner fin a la actividad a la que había dedicado toda su vida y que más placer le aportaba, conduciéndola a un retiro forzoso y doloroso. La relación emocional con su mundo narrativo era tal que cuando se vio privada de la escritura y debido a la confusión mental propia de su enfermedad, confundía realidad y ficción y hablaba sobre sus personajes como si fueran personas reales.

En la actualidad, gracias a la obra de algunos escritores que han padecido la enfermedad de Alzheimer, los investigadores disponen de una extensa documentación que les permite avanzar en el conocimiento del desarrollo de esta enfermedad en su manifestación escrita. Iris Murdoch ya contaba con el diagnóstico clínico de su enfermedad cuando The Cognition and Brain Sciences Unit del University College de Londres trató de encontrar en su obra signos que evidenciaran un diagnóstico ya conocido. El grupo de investigadores de Londres realizó un estudio de la narrativa, comparando el estilo

1 Editado en español por Lumen (2007) bajo el título El príncipe negro.

2 Trad.: «sentía esos oscuros glóbulos en la cabeza, ese cosquilleo en los dedos que presagia el advenimiento de la inspiración» (Murdoch, 2009: 293). 
de su última obra Jackson's Dilemma y dos anteriores, en concreto Under the Net, que fue su primera novela, y The Sea The Sea, escrita en su momento más creativo. Las novelas fueron digitalizadas y tratadas con un software de análisis textual. La conclusión a la que se llegó fue que aunque en su última novela la estructura y la gramática permanecían invariables, su vocabulario disminuía y su lenguaje era mucho más simple (Garrard et al., 2005: 258).

Este tipo de estudios lingüísticos resultan de gran importancia para la medicina, ya que ayudan a los investigadores a mejorar los exámenes neuropsicológicos que se emplean para diagnosticar esta demencia. Así pues, Iris Murdoch no solo dejó a sus lectores un gran legado literario y filosófico, sino que además dejó a los científicos, a través de su obra, algunas claves para estudiar la evolución de la enfermedad de Alzheimer.

\section{ALZHEIMER Y CREATIVIDAD}

Hoy en día la enfermedad de Alzheimer ha dejado de ser un problema exclusivamente médico para pasar a ser un problema social. Si bien es verdad que al darse un notable incremento de la población de más edad en los países desarrollados, donde cada vez es mayor la incidencia de esta enfermedad, tampoco hay que olvidar que según estudios epidemiológicos de 2011 de la Organización para la Cooperación y Desarrollo Económicos (OCDE), publicados por la Organización Mundial de la Salud, esta proporción representa menos del 7\% de personas entre 65 y 80 años. A partir de los 85 años se estima que un $25-30 \%$ de las personas padecen demencia ${ }^{3}$. Este es un dato fundamental para no llegar a conclusiones equívocas, como por ejemplo que el Alzheimer sea una enfermedad generalizada que afecta a todas las personas mayores, como se puede llegar a concluir dada la considerable atención que está recibiendo la enfermedad en los medios de comunicación. El envejecimiento fisiológico no es la causa de la enfermedad de Alzheimer, ni la enfermedad de Alzheimer una consecuencia natural de la edad, aunque esta sea el principal factor de riesgo de esta patología.

La enfermedad de Alzheimer afecta a todo tipo de personas con independencia de su raza, clase social o capacidades intelectuales. Por ello, el mundo de las letras, donde la actividad cognitiva es decisiva, también se ha

3 La demencia más frecuente $(60 \%$ de los casos) es la enfermedad de Alzheimer. Al no ser de declaración obligatoria, no existen registros oficiales y resulta muy difícil calcular la frecuencia de dicha enfermedad (Algado et al., 1996: 86). 
visto afectado por la enfermedad. Sin embargo, hay datos epidemiológicos que indican que si bien no exime de padecerla, cuanto mayor es el nivel educativo, menor es la probabilidad de sufrir demencia en edades avanzadas (Qiu C. et al., 2001). Ello nos lleva a considerar una de las recomendaciones que se indican para la prevención del deterioro cognitivo: mantener la mente ágil. La actividad mental es decisiva debido a la neuroplasticidad cognitiva. Como explica el neurólogo José Manuel Martínez Lage (2001), gracias al aprendizaje, en el cerebro se forman más sinapsis o puntos de conexión entre neuronas. Los estudios clínicos demuestran otra hipótesis: a mayor reserva cognitiva más se retrasan los síntomas de la demencia. Si se llega a la vejez con muchas neuronas y muchas sinapsis, se tolerarán mejor los síntomas de la EA porque se tendrá más reserva cognitiva. Las facultades intelectuales de Iris Murdoch, apuntadas en la presentación de este trabajo, debieron de desempeñar un papel fundamental en su reserva cognitiva, retrasando la aparición de los primeros síntomas de su enfermedad o en todo caso habrían ralentizado su deterioro.

Pese a esta reserva cognitiva, cada vez es más frecuente encontrar a grandes autores literarios que padecen o han padecido esta devastadora enfermedad a través de los tiempos. Cuando aún no se le había puesto nombre a esta patología y la investigación médica no mostraba tanta preocupación por la pérdida de memoria, el autor irlandés Jonathan Swift (1667-1745) pudo ser una de sus presas. Como señalan Miranda, Pérez y Slachevsky (2011: 397) antes de su muerte sus familiares describían su estado con síntomas típicos de la enfermedad de Alzheimer: cambio de memoria, trastorno del comportamiento y pérdida de autonomía. Incluso en su afamada obra escrita hace más de 250 años, Los viajes de Gulliver, y en concreto en el tercer viaje del protagonista (cuando visita la isla de Glubbdubdrib), Swift sin saberlo contribuye a la ciencia ofreciendo al lector lo que podría considerarse una de las primeras descripciones médicas de la demencia. El autor define así a los Struldbrughs cuando llegan a los 90 años:

When talking, they forget the common appellation of things, and the names of persons, even of those who are their nearest friends and relations. For the same reason, they never can amuse themselves with reading, because their memory will not serve to carry them from the beginning of a sentence to the end (Swift, 1992: 161)4.

${ }^{4}$ Trad.: «Al hablar ellos olvidan el nombre de las cosas y el de las personas, incluso aquellos más cercanos y parientes. Por la misma razón no se entusiasman con lo que leen, debido a que la memoria no les ayuda a recordar lo que recién han leído al terminar apenas una oración» (Swift, 1987: 342). 
También es probable que el escritor, filósofo y poeta estadounidense Ralph Waldo Emerson (1803-1882) padeciera la enfermedad de Alzheimer, entonces considerada genéricamente trastorno senil y de poco interés para el público en general. Ross Macdonald (seudónimo de Kenneth Millar) (19151983), autor clave de la literatura negra norteamericana, tuvo que dejar de escribir a los 55 años a causa de esta enfermedad. El dramaturgo estadounidense Abe Burrows (1910-1985), ganador del premio Pulitzer de teatro en 1962, murió en 1985 aquejado por esta misma enfermedad, así como el escritor también estadounidense Elwyn Brooks White (1899-1985). En España podemos citar el caso de la escritora y poeta Carmen Conde (1907-1996), la primera mujer académica de la Real Academia Española, quien mostró los primeros síntomas de la enfermedad de Alzheimer en 1982.

Más recientemente, en el año 2007 el escritor británico Terry Pratchett (1948), creador de la saga Discworld y segundo autor de ficción en el ranking de ventas en Reino Unido tras J.K. Rowling, anunció en su página web que padecía Alzheimer. El autor se enfrentó a la enfermedad y no tuvo problemas en hacerla pública, algo que sorprende aún en nuestros días. En España tenemos el caso del político Pascual Maragall que en el año 2007 también anunció públicamente que le habían diagnosticado la enfermedad. Gracias a casos como el suyo, las enfermedades mentales dejan de ser tabúes y la sociedad empieza a hablar de ellas con naturalidad, sin necesidad de ocultarlas ni avergonzase de padecerlas. Gracias a esta nueva percepción de la enfermedad, el sufrimiento de las personas que la padecen suscita mayor comprensión. No obstante, el tema de si las enfermedades de las personas públicas deben mantenerse en privado ha sido y es muy cuestionado. John Bayley, marido de la escritora, no quiso ocultar la verdad y afrontó la enfermedad de su esposa públicamente, por lo que fue muy elogiado, pero también muy criticado. Desgraciadamente, aún existe un sector que tiende a silenciar las enfermedades o hablar de ellas de forma encubierta, sin nombrarlas o mediante eufemismos, lo que no contribuye en absoluto a erradicar el estigma social asociado a la enfermedad.

Quizá sea este el caso de Gabriel García Márquez, sobre el que ha saltado la alarma de que pudiera padecer algún tipo de demencia, apuntándose a la enfermedad de Alzheimer, pero sin que nada se haya confirmado. El premio Nobel de ochenta y seis años ya conoce de cerca la demencia, ya que su madre y su hermano también la sufrieron. El ejemplo de García Márquez nos hace viajar al Macondo, de Cien años de soledad, y en concreto al episodio en que una plaga de insomnio asola el pueblo haciendo que sus habitantes olviden el nombre de las cosas. José Arcadio Buendía, en su lucha 
contra esta pérdida de memoria semántica (Rascovsky et al., 2009: 2610), se ve obligado a etiquetar cada objeto llegando a construir lo que denomina la máquina de la memoria:

$[D]$ escubrió que tenía dificultades para recordar casi todas las cosas del laboratorio. Entonces las marcó con el nombre respectivo, de modo que le bastaba con leer la inscripción para identificarlas. Cuando su padre le comunicó su alarma por haber olvidado hasta los hechos más impresionantes de su niñez, Aureliano le explicó su método (García Márquez, 1984: 102).

Aunque esta patología no coincida exactamente con la enfermedad de Alzheimer, sino con una demencia semántica descrita después en neurología, sí es cierto que ambas comparten esta pérdida de memoria que definiría el estado actual del escritor. De hecho, los pacientes con demencia semántica conservan la memoria autobiográfica reciente, pero, sin embargo, al igual que las personas con Alzheimer, no recuerdan episodios de su infancia o de su primera etapa de adultos, algo que también queda patente en la novela de García Márquez cuando Visitación advierte que la peste del insomnio conduce al olvido:

Cuando el enfermo se acostumbraba a su estado de vigilia, empezaban a borrarse de su memoria los recuerdos de la infancia, luego el nombre y la noción de las cosas, y por último la identidad de las personas y aun la conciencia del propio ser, hasta hundirse en una especie de idiotez sin pasado (García Márquez, 1984: 99).

En este terreno lingüístico y literario, también encontramos el caso de la escritora en lengua inglesa Agatha Christie (1890-1976), que cuenta con una extensa producción literaria: escribió sesenta y nueve novelas y diecinueve obras de teatro. Algunos de sus biógrafos sospechaban que podría haber padecido la enfermedad de Alzheimer, aunque nunca le fue diagnosticada. Fue un grupo de lingüistas de la universidad de Toronto, encabezados por Lancashire y Hirst (2009), los que años después de su muerte ejercieron la función de médicos. En este caso la lingüística suplantó a la medicina, sustituyendo instrumentos como escáneres o pruebas médicas por software informático especializado. Al igual que en el caso de Iris Murdoch, se escanearon quince de las novelas que la escritora escribió entre los 28 y 82 años. Siguiendo un método inductivo, el estudio de su obra permitió realizar el diagnóstico de la enfermedad. 
El deterioro cognitivo propio de las primeras etapas de la enfermedad de Alzheimer se refleja en el análisis lingüístico que llevaron a cabo estos investigadores. De hecho, el deterioro resultaba evidente cuando la escritora ya había cumplido setenta años y ya había escrito gran parte de su obra. Se apreciaron objetivamente cambios de estilo en su escritura que podían ser indicadores de déficits cognitivos típicos de la demencia que padecía: el vocabulario iba disminuyendo con la edad al tiempo que aumentaba la repetición de palabras y el uso de sustantivos vagos. En la novela en la que más se observaron estas características fue paradójicamente en Elephants Can Remember ${ }^{5}$, escrito a sus ochenta y un años. Comparándola con las obras que escribió a los sesenta y tres años, el vocabulario disminuyó un 30\% y presentaba un $18 \%$ más de frases repetidas. Bien es verdad que en el caso de Agatha Christie la enfermedad tardaría en mostrar su peor cara, ya que como revela Rosa Montero (1998) con ochenta años aún leía a autores como Marcuse, Chomsky, Freud, Jung, Moore, Wittgenstein o Dunne. Su última novela, Curtain (1974) $)^{6}$ aunque retocada por sus editores, se publicó un año y medio antes de morir, a los ochenta y cinco años.

El profesor Pascual Cantos (2010) también se ha dedicado al campo de la lingüística computacional, elaborando un análisis longitudinal de los discursos políticos del ministro británico Harold Wilson, correspondientes al periodo anterior a su diagnóstico como enfermo de Alzheimer, explorando cómo podía haberlo afectado la enfermedad en su fase inicial. A diferencia de otros estudios, el suyo se ocupa del lenguaje oral y el discurso espontáneo, demostrando cómo la expresión oral también muestra síntomas de la enfermedad. Igualmente señala la importancia de la reserva cognitiva, gracias a la cual nadie se dio cuenta de los primeros indicios de su enfermedad.

El discurso sobre la enfermedad de Alzheimer se ha enriquecido al traspasar el límite de la biomedicina y extenderse a otras disciplinas, como la sociología, psicología, linguística, pintura, literatura... En el terreno artístico la obra de la última etapa del pintor expresionista abstracto Willem de Kooning (1904-1997), realizada cuando padecía la enfermedad de Alzheimer, ha sido muy controvertida. Pia C. Kontos (2003: 164) expone que, a pesar de su deterioro cognitivo y en contra de todo pronóstico sustentado por la idea de que la demencia conduce al declive de todas las expresiones creativas, de Kooning mantuvo su creatividad artística. Sorprendentemente,

5 Editado en español por Planeta (1972), bajo el título Los elefantes pueden recordar.

6 Editada en español por Molino (1975), bajo el título Telón. 
se produjo un cambio de estilo en su obra, que incluso llevó a algunos críticos a dudar de la autoría de sus cuadros ${ }^{7}$. Este hecho ofrece una nueva mirada sobre la noción restrictiva de la personalidad y despersonalización de los enfermos de Alzheimer que sostienen las narrativas dominantes, según las cuales lo que constituye la personalidad del ser humano se pierde en el transcurso de esta patología

\section{LA ENFERMA FRENTE A LA ESCRITORA}

Aunque muchas de sus novelas hayan sido traducidas al castellano, en España Iris Murdoch no ha tenido el eco y el reconocimiento que sí le ha otorgado la literatura británica. Hoy en día el público español reconoce más a Murdoch como una enferma de Alzheimer que como una excelente escritora y filósofa. En gran parte puede deberse a la obra que escribió John Bayley y que se publicó el mismo año de la muerte de su esposa, Elegy for Iris ${ }^{8}$ (Bayley, 1999), un best seller que ese mismo año se tradujo al castellano y qué más tarde sería adaptada al cine.

Elegy for Iris son unas memorias de gran carga emotiva en las que el autor narra en primera persona su vida junto a Iris Murdoch, centrándose en sus experiencias durante los últimos años que pasó entregado a su cuidado, pero refiriéndose también a su vida en común antes de la enfermedad a través de relatos retrospectivos. Cuando el debilitamiento de la escritora le impide poner su voz para contar su propia historia, es su marido quien decide tomar el relevo y le presta la suya propia, redefiniendo así su nueva relación: Bayley escribe desde la posición del Yo sano y confiere a la escritora el papel desempoderado de el Otro. De esta forma, Bayley, que como escritor siempre había estado relegado a la sombra de su esposa como el marido de la gran Iris Murdoch, pasó a primer plano e incluso se encargó de responder a la correspondencia privada que mantenía su esposa con los lectores de su obra. Al tratarse de una persona sana y autónoma, Bayley pudo valerse de sus herramientas cognitivas y lingüísticas para tratar de expresar el sentir de su esposa enferma y dependiente, que permanecía en silencio, apartada de la escritura y abocada a lo que algunos autores han denominado muerte social (Sweeting y Gilhooly, 1997). Estos autores observaron cómo para algunos cuidadores el enfermo de Alzheimer quedaba reducido a un cuerpo físico en

7 A su vez la banda galesa de música Manic Street Preachers dedicó al artista su canción His Last Painting centrada en la obra de esta última etapa de De Kooning.

8 Editada en español por Alianza (1999) bajo el título Elegía a Iris. 
el que la persona había desaparecido, por lo que solo se ocupaban de sus cuidados corporales olvidando su vida psíquica, lo que les llevaba a internarlo en una institución. Aunque la narración de Bayley no se cierra con la muerte biológica de la escritora, sino unos meses antes, sabemos que se mostró reticente a ingresarla en una institución, lo que hubiera podido aumentar su confusión y desorientación, y se ocupó de su cuidado integral hasta tres semanas antes de su muerte, cuando finalmente Iris Murdoch tuvo que ser ingresada en Vale House, una instalación hospitalaria especializada en cuidados a enfermos con demencia.

Elegy for Iris pertenece a una nueva categoría narrativa sobre enfermedades, que ocupa un espacio entre lo personal y lo profesional. La publicación del libro fue muy aplaudida por parte del público, ya que contribuyó a dar una visión realista y personal de la enfermedad, sin reducir toda su complejidad a aspectos puramente neurobiológicos, centrándose en la observación y el análisis del estado físico y psicológico de la persona enferma. Sin embargo, todas las autobiografías son narrativas problemáticas no exentas de críticas, dado que la memoria es siempre parcial y selectiva y la voz narrativa siempre se posiciona ideológicamente. Muchos lectores tacharon a Bayley de traición y falta de ética, una actitud que contrastaba con el respeto a la dignidad de su esposa que le brindó durante su enfermedad. Se le reprochó su indiscreción al exponer a la mirada pública el deterioro de Iris Murdoch, desconociendo si ella hubiera consentido que salieran a la luz detalles humillantes de su vida íntima. La propia escritora, que siempre protegió su privacidad, había expresado en una ocasión en 1971 «there are not many people whom one wants to know one!» ${ }^{9}$ (Conradi, 2010: 528). Su poco afán de protagonismo se refleja en el hecho de que dejara escrito su deseo de que nadie acudiera a su cremación ni a esparcir sus cenizas, ni siquiera que se celebrara un funeral por ella, lo que hace pensar al lector que tampoco le hubiera gustado que se contara su vida como enferma.

A.S. Byatt, escritora, crítica literaria y amiga de Iris Murdoch, en una entrevista publicada en un periódico (The Guardian, 25 de abril de 2009), criticaba duramente a J. Bayley: «what he did was wicked [...] I knew her enough to know that she would have hated it» ${ }^{10}$. Calificó la publicación del libro como imperdonable, ya que, por una parte, Murdoch era una escritora sin prejuicios, pero evitaba escribir novelas autobiográficas, ya que conside-

9 Trad. de la autora del artículo: «No hay muchas personas que quiero que me conozcan».

10 Trad. de la autora del artículo: «Lo que hizo fue ruin. [...] La conocía lo suficiente como para saber que no le habría gustado nada». 
raba que como autora no debía aparecer en sus libros. De hecho tampoco conocemos ningún escrito sobre su propia experiencia como cuidadora de su madre, sumida en la misma enfermedad que la propia Murdoch padecería más adelante. Por otra parte, Byatt mostró su desagrado por el efecto que el libro provocó: «a horrible effect on how people feel about her and see her and think about her» ${ }^{11}$. Algo parecido opina Robert Weil (Murdoch and Dooley, 2003: XXIV), al afirmar que prestar demasiada atención al declive de los últimos años de Murdoch constituiría una espantosa trivialización de una extraordinaria trayectoria académica. También algunos amigos de Iris Murdoch acusaron a Bayley de distorsionar la figura de su esposa, que no se correspondía con la real, ya que al situarla en un papel de enferma dependiente de su marido proyectaba una imagen de alguien con un nivel intelectual muy inferior a la real, al tiempo que él mismo nos recuerda que además de crítico literario también es escritor. Sin embargo su mayor notoriedad como escritor le llegaría gracias a este libro, refiriéndose a la figura de su esposa. Distinta fue la visión mucho más objetiva que ofreció su amigo y gran admirador Peter J. Conradi, al que se le encargó la fascinante tarea de escribir la biografía autorizada de la autora: Iris Murdoch: A Life (2010), en la que si bien aparecen datos íntimos desconocidos hasta entonces sobre la vida de escritora antes de su enfermedad, sabemos que contó con su aprobación y que tuvo acceso a cartas y diarios no publicados que ella misma había escrito durante toda su vida. Ambos escritores nos ofrecen visiones distintas de la autora: mientras Bayley nos descubre a Iris Murdoch como enferma de Alzheimer, Conradi nos muestra a la escritora y pensadora.

Sin embargo, no todo fueron críticas a la obra de Bayley. Al igual que ocurre con otras narrativas de cuidadores, su escritura no solo supuso una terapia para su autor, que al contar su historia pudo transformar sus emociones en palabras y dar sentido a sus vivencias. Además, muchos receptores consideraron Elegy for Iris una narrativa terapéutica, ya que el autor reflexiona sobre cómo afecta esta compleja enfermedad a la propia persona enferma y a su entorno, resaltando la importancia del apoyo social y familiar, que, en su caso, al tratarse de un matrimonio sin hijos y ser Iris hija única, recayó sobre él. Muchos cuidadores y familiares de personas con EA encontraron apoyo emocional en la figura de John Bayley, en su tarea de cuidador principal, agotadora y muchas veces frustrante, con cargas tanto objetivas como subjetivas, un concepto que la literatura médica ya ha eti-

11 Trad. de la autora del artículo: «Un efecto terrible sobre lo que la gente percibe de ella, lo que piensan de ella». 
quetado como «síndrome de carga del cuidador» o SCC (Zambrano Cruz \& Ceballos Cardona, 2007: 26). Mostraron su agradecimiento por hacer público su testimonio personal rompiendo así el tabú en torno a las demencias. La narración personal y cercana convierte a los lectores en testigos de una experiencia subjetiva, acercándolos a esta patología a través de la persona que la padece, sin que tengamos que pasar por manuales científicos ni etiquetas teóricas, reduciendo así el estigma asociado a las personas con demencia y sacándolas de los márgenes del discurso donde suelen estar ubicadas $^{12}$. De este modo, la narrativa estaría contribuyendo a comprender mejor la enfermedad de Alzheimer, actuando como una herramienta más de comunicación y educación.

El amargo periodo de la enfermedad de Iris Murdoch también debió de dejar huella en A.S. Byatt, que la consideraba su madre literaria. Su relato «The Pink Ribbon», que cierra la colección de cuentos Little Black Book of Stories (2005) ${ }^{13}$, está protagonizado por un matrimonio mayor formado por Mado, una mujer que padece la enfermedad de Alzheimer y James, su marido y único cuidador, que ve cómo la enfermedad va avanzando, transformando a su esposa en otra persona. Quizá A.S. Byatt estuviera rindiendo tributo a su amiga a través de este relato. Llama la atención la alusión que se hace a los Teletubbies, que también aparece en Elegy for Iris. Mado, como la propia Iris Murdoch durante su enfermedad, encuentra gran placer viendo este programa infantil. Resulta paradójico que una intelectual de la categoría de Murdoch, que además despreciaba la televisión y nunca había tenido una porque temía que el mundo terminara en poder de este medio, acabara su vida como una niña hipnotizada por estos coloridos personajes que lograban calmar su ansiedad.

El discurso biomédico dominante sostiene que un enfermo de Alzheimer pierde su yo al perder la memoria, despojándolo de aquellas características que pueden definir su identidad, por lo que primero moriría «el ser», dejando solo un cuerpo vacío hasta el momento de la muerte física, una especie

12 No es el único ejemplo de narrativa personal sobre esta enfermedad. Para ilustrar la importancia de este tema en la literatura contemporánea podemos citar obras como El diario de Noa (1996), de Nicholas Sparks o Mi madre (2009), de Tahar Ben Jelloun. Destaca la autora de Still Alice (2009), Lisa Genova, ya que además de escritora es neuróloga. En España podemos citar a la poeta Juana Castro, con Los cuerpos oscuros (2005); Identidades perdidas (2004), de María Dolores Boixadós; Ejercicios de memoria (2008) de José María Conget o El oscurecer: un encuentro (2002) de Luis Mateo Díez. Incluso el escritor soriano Antonio de Benito se atreve a acercar el Alzheimer a los niños en Oyendo campanas (2010).

13 Editada en español por Alfaguara (2007), bajo el título El libro negro de los cuentos. 
de muerte en vida. Como sostienen McColgan, Valentine y Downs (2000: 100) esta representación centrada en la enfermedad y sus aspectos deficitarios, excluyendo al enfermo como persona, ha reforzado la imagen negativa de muerte social del sujeto enfermo. Sin embargo, Bayley (1999: 59) discrepa de este estereotipo pasivo en su narración, ofreciendo una visión más humanizada y menos amarga. Iris Murdoch, pese a su déficit cognitivo, en cierto modo conservó su personalidad hasta el final, manteniendo e incluso acentuando algunos rasgos identificativos a través del tiempo, lo que concuerda con el modelo de identidad propuesto por Giddens (citado en Hockey and James, 2003: 204), basado en la continuidad y mutabilidad. Era una mujer con síntomas de demencia, pero seguía estando ahí. Su silencio no conllevaba que pudiera seguir pensando ni que hubiera perdido su ser. Basándose en su experiencia, Bayley advierte al lector de que la enfermedad solo consiguió acentuar la bondad natural que siempre la había caracterizado.

La desocialización del enfermo de Alzheimer es uno de los primeros estigmas que plantea esta condición. Sin embargo, de nuevo Bayley afirma que Iris Murdoch tampoco perdió sus reflejos en situaciones de intercambio social ni dejó de ser amable y siguió siendo la misma en muchos aspectos (1999a: 40). Tampoco comulga con el principio según el cual la persona con demencia pierde la habilidad para comunicarse. Bayley se esforzó por decodificar y comprender el nuevo lenguaje de su esposa enferma. Lo que cambiaba era la forma de comunicación: cuando la afasia le hizo perder sus habilidades verbales, se comunicaba con el mundo de una forma no verbal: mediante la expresión de emociones, gestos, sonrisas, afecto y contacto físico. Estos contactos sociales le ayudaron a conservar su identidad, ya que como actualmente se piensa (Hockey and James, 2003: 6) la identidad emerge a través de las relaciones sociales. Según se desprende de Elegy for Iris, Bayley se esforzó por aumentar su calidad de vida y mantener la personalidad de su esposa. Para ello estableció un ambiente y unas rutinas diarias que pudieran resultarle familiares, comunicándose con ella y tratándola no como una enferma, sino como una persona que conservaba su yo, como la mujer que siempre fue. También Peter Conradi afirma que su esencia permaneció, y que su bondad natural sobrevivió a su enfermedad. McColgan et al. (2000: 104) analizan la imagen de la escritora en una fotografía tomada durante su enfermedad, en la que muestra un semblante sereno y bondadoso alejado de cualquier rasgo de miedo.

Las memorias de J. Bayley dieron lugar a una adaptación cinematográfica, dirigida por Richard Eyre, dos años después de la muerte de la escritora, Iris (Eyre, 2002), película que aumentó la conciencia pública de Iris 
Murdoch como enferma de Alzheimer, conectando cine y literatura con el mundo real ${ }^{14}$. Iris pertenece al género que se conoce como biopic (término del inglés biographic picture), situado entre la biografía y la ficción, muy de moda en nuestros días. En ella se cuenta la historia de los últimos cuarenta años de la vida de Murdoch, desde el momento en que conoció a John Bayley, dando unas pinceladas a su vida anterior y centrándose en su deterioro a causa del Alzheimer. La juventud de Iris contrapone su riqueza intelectual con lo que devino por los devastadores efectos de la enfermedad. La película destaca por las interpretaciones de las actrices que dan vida a la escritora: la Iris joven y promiscua fue interpretada por Kate Winslet y la Iris mayor con demencia por Judi Dench. Con la elección de dos actrices distintas queda trazada la brecha en la vida de la escritora: su vida antes y después de la enfermedad, transformada en una identidad distinta, considerando que la identidad no es algo fijo y asignado, sino cambiante. Judi Dench fue tan aclamada por su interpretación de la escritora que en el año 2003 fue invitada a inaugurar el centro dedicado al estudio de la demencia «Iris Murdoch Building», situado en la universidad de Stirling (Gran Bretaña). Esta misma universidad acaba de concederle el título de doctora honoris causa por su contribución a las artes, especialmente al cine.

$\mathrm{Al}$ igual que el libro en que se basa, la película muestra algunos detalles muy íntimos y crueles de los últimos años de la vida de Iris Murdoch. Algunos están basados en el libro, otros han sido inventados o retocados por el director de la película, por lo que navega entre la biografía y la ficción. Desgraciadamente la película simplifica mucho la figura de Murdoch, sin que se muestre su genialidad como escritora y filósofa, centrándose en su lucha contra la enfermedad de Alzheimer y dejando totalmente de lado la faceta por la que tanto destacó en la literatura.

La película, como el libro de Bayley, también constituye una herramienta educativa alternativa. Las narrativas personales sobre enfermedades aportan una información valiosísima para la atención del paciente, más allá de publicaciones médicas, estudios de investigación, datos clínicos o entrevistas a médicos, lo que uno de los personajes de Murdoch denomina «the cool eye of science» (Murdoch, 1974: 58) ${ }^{15}$. Teniendo en cuenta este planteamiento, la universidad Goethe de Francfort Main incluyó Iris como recurso

14 El cine se ha hecho eco de la enfermedad de Alzheimer a través de películas como la española ¿Y tú quién eres? de Antonio Mercero (2006), El hijo de la novia, de Juan José Campanella (2000) o The Iron Lady, de Phyllida Lloyd.

15 Trad.: «el frío ojo de la ciencia» (Murdoch, 1980b: 79). 
educativo para el aprendizaje (así como otras películas de temática similar) en el temario de los estudiantes de un curso universitario de Farmacia. También la Universidad de Barcelona incluye la película como parte de la información básica de la asignatura de Enfermería de Salud Mental, ayudando a los estudiantes a comprender mejor la demencia y otras patologías a través de representaciones de experiencias personales.

\section{MEMORIA Y OLVIDO EN LA OBRA DE IRIS MURDOCH}

Este trabajo comienza con la idea de que los textos de muchos enfermos de Alzheimer constituyen un valioso corpus con el que investigar algunos síntomas de la enfermedad. Son, además, un instrumento de empoderamiento, mediante el cual la persona enferma puede expresarse y ocupar el centro del discurso en aquellos casos en que sea consciente de su patología y ésta aún le permita escribir. Como se ha mencionado anteriormente, la enfermedad de Alzheimer presenta como síntoma inicial y dominante la pérdida de memoria. A pesar de que la literatura biomédica pone en duda si la persona con Alzheimer tiene o no conciencia de su enfermedad, según se desprende de Elegy for Iris y de su biografía autorizada, Murdoch tenía vida interior y era consciente de su condición cuando expresaba que no tenía «memory, no continuity, no identity ${ }^{16}$ (Conradi, 2010: 24). Pero la vida de Iris Murdoch está muy documentada, ya que durante toda su vida escribió diarios personales que constituyeron una fuente de información biográfica permitiendo a escritores como Conradi o Bayley acceder a su yo pasado y recuperar sus recuerdos para reconstruir su identidad a partir de estas narrativas, dándoles continuidad. Cuando la demencia le impide expresarse a través del lenguaje, escuchamos la voz de Iris Murdoch en otras voces. Su biógrafo, Peter Conradi, expresaba con gran tristeza que, mientras Iris Murdoch perdía su memoria, él la recuperaba «As she gradually forgot her past, I rediscovered it. It sometimes seemed as if I were becoming her memory ${ }^{17}{ }^{12010: 21)}$.

La obra literaria de Iris Murdoch nos permite investigar percepciones y actitudes sobre la memoria y el olvido. A través de una selección de sus textos literarios observamos el aprecio que sienten muchos de sus personajes por la memoria, el aspecto de la personalidad que mejor define al ser humano. Una memoria que la escritora fue perdiendo hasta llegar a una

16 Trad. de la autora del artículo: «memoria ni continuidad ni identidad».

17 Trad. de la autora del artículo: «A medida que ella iba olvidando su pasado, yo lo iba redescubriendo. A veces parecía como si me estuviera convirtiendo en su memoria». 
profunda amnesia que le hizo olvidar el título de sus libros e incluso que había sido escritora. Cuando escribió Bruno's Dream (1969) ${ }^{18}$, Murdoch tenía 50 años y la enfermedad de Alzheimer, aunque quizá ya latente, aún no había mostrado síntomas. Ni siquiera su madre había empezado a mostrar los primeros síntomas de su demencia. Sin embargo, este libro narra con asombroso realismo el problema de la pérdida de la memoria, aunque en este caso no como una patología de tipo degenerativo. Más bien se trataría de un deterioro cognoscitivo secundario a la enfermedad que padecía su protagonista, Bruno Greensleave, que pudiera ser un tumor cerebral, dada la hidrocefalia que se describe en la novela que lo va trasformando hasta convertirlo físicamente en un monstruo. Murdoch representa de este modo la otredad en que la pérdida de salud sume al enfermo: se convierte en una monstruosidad de difícil inclusión social. Bruno es un anciano nonagenario cuya enfermedad lo mantiene postrado en su cama. Las facultades mentales del protagonista no se encuentran dañadas hasta el momento de su muerte, y razona con claridad hasta las últimas páginas del libro. La cuestión que se plantea Bruno al inicio de la novela sobre el envejecimiento del cerebro humano hace pensar al lector en el devenir de su autora:

One million brain cells were destroyed every day after the age of twentyfive. Danby had told him once, having read it in the Sunday paper. Could there be any brain cells left at that rate when one was well over eighty? (Murdoch, 1976: 6) ${ }^{19}$.

Aunque hoy en día esta afirmación sobre el envejecimiento del cerebro humano ha sido rebatida por muchos investigadores (Marian Diamond 1985, citado en Friedman 1994: 103) que sostienen que la plasticidad del cerebro puede compensar este proceso, el suicidio de las neuronas pudiera haber inquietado entonces a Iris Murdoch.

En Bruno's Dream aparece un personaje secundario que merece nuestra atención: la supuesta tía de los gemelos cuidadores de Bruno, un personaje cómico al que se alude siempre con humor e ironía, rompiendo así la angustia que produce la proximidad de la muerte del protagonista y otorgando al lector un momento de relax. Se trata de una mujer que los gemelos adoptaron

18 Editada en español por Lumen (2006), bajo el título El sueño de Bruno.

19 Trad.: «Una vez Danby le había contado que a partir de los 25 años cada día se destruyen un millón de células cerebrales; lo había leído en el periódico del domingo. A aquel ritmo, ¿podían quedar células cuando se llegaba a los ochenta?» (Murdoch, 2006: 21). 
hace tiempo como tía y que aparentemente presenta un cuadro médico que podría responder a la enfermedad de Alzheimer u otro tipo de demencia:

-My auntie's senile. She's got completely gaga. She thinks she is a Russian princess. She talks some sort of gibberish she thinks is Russian.Funny how mad people go for titles (Murdoch, 1976: 24) ${ }^{20}$.

En algunos momentos la tía muestra demencia semántica, una pérdida de conocimiento del significado de las palabras:

Of late even her ability to talk seemed to be deserting her. In shops she mumbled and pointed to what she wanted, or uttered a stream of gibberish with Russian sounding endings (Murdoch, 1976: 43) ${ }^{21}$.

Aunque la tía hace años que ya no habita en el mundo real, no lo vive con angustia ni ansiedad. Solo escuchamos su voz a través de sus sobrinos: sabemos que aún es capaz de ocuparse de su casa, y que la pérdida de la razón no le ha hecho desgraciada. Irónicamente, uno de sus sobrinos le increpa: «stop gibbering Auntie, or we'll put you in a bin. Go and write your memoirs!» ${ }^{22}$ (Murdoch, 1976: 42). Sorprende que una mujer que aparentemente ha perdido sus facultades mentales y vive en un mundo imaginario esté escribiendo sus memorias, obsesionada y fascinada con su pasado. Precisamente los enfermos de Alzheimer son grandes creadores de historias, ya que, para poder encajar el momento presente y hacerlo más agradable, se inventan historias paralelas, muchas veces a partir de restos del pasado. Casualmente en dos de las novelas más galardonadas de Iris Murdoch, The Black Prince y The Sea The Sea, los protagonistas masculinos, en plenas capacidades mentales, se dedican a escribir formalmente sus memorias. Bradley Pearson, el protagonista y voz narrativa de The Black Prince lo justifica explicando que «one's capacity to forget absolutely is immense $»^{23}$ (Murdoch, 2003: 8).

20 Trad.: «Mi tía está chocha. Está completamente ida. Cree que es una princesa rusa. Habla una especie de galimatías y cree que es ruso»

«Es divertido ver lo que les gustan los títulos a los locos» (Murdoch, 2006: 44).

21 Trad.: «Últimamente incluso su capacidad de hablar parecía haberla abandonado. En las tiendas señalaba las cosas que quería con gestos o balbucía una jerigonza cuyos finales sonaban a ruso» (Murdoch, 2006: 67).

22 Trad.: «deja ya esa jerga tía, o te encerraremos en un baúl. ¡Vete a escribir tus memorias!» (Murdoch, 2006: 67)

23 Trad.: «La capacidad que tenemos de olvidar por completo es inmensa» (Murdoch, 2009: 10). 
Cuando se aproxima el final de Bruno's Dream, en medio de una gran carga trágica, Murdoch permite al lector una última sonrisa, dando un giro inesperado a la figura de la tía y su aparente deterioro cognitivo, confundiendo realidad y fantasía: «Auntie's memoirs too, when translated into English, proved a best seller, as well as being a mine of information for historians about the last days of the Czarist regime» ${ }^{24}$ (Murdoch, 1976: 279). Tras este guiño, en el que se revela que en realidad la tía no había perdido sus facultades mentales, nos movemos de lo cómico a lo trágico, para encontrar a Bruno en sus últimos momentos devorado por la angustia:

He felt as if the centre of his mind was occupied by a huge black box which took up nearly all the space and round which he had to edge his way. Names not only of people but of things eluded him, hovering near him on the left, on the right, like birds which sped away when he turned his head (Murdoch, 1976: 265) 25 .

Los pensamientos de Bruno se convierten en una profecía del devenir de su autora. No podemos dejar de pensar en que Iris Murdoch tendría más adelante una vivencia parecida de su propia enfermedad. La imaginamos en su angustiosa búsqueda por encontrar las palabras adecuadas mientras escribía Jackson's Dilemma, cuando la caja negra del olvido fuera creciendo hasta apoderarse por completo del espacio de su mente: «I don't have a world ${ }^{26}$ (Conradi, 2010: 596), afirmaba lamentándose por su incapacidad para escribir. La narrativa de Bruno se convierte en las palabras que Iris Murdoch ya no sería capaz de articular años después. Nos parece escuchar su voz en los pensamientos de Bruno en la antesala de su muerte, un momento que Elizabeth Dipple (1982: 175) define con el término médico de tanatopsia ${ }^{27}$ : «Somewhere quite else there was the past, perfectly clear, brightly coloured, stretching out near to him in some sort of different kind of extension. He saw moving pictures. It was not quite like remembering ${ }^{28}$

24 Trad.: «Las memorias de la tía, una vez traducidas al inglés, resultaron un gran éxito y constituyeron una mina de información para los historiadores respecto a los últimos días del régimen zarista» (Murdoch, 2006: 366).

25 Trad.: «Sentía como si en el centro de su mente se emplazara una inmensa caja negra que ocupase casi todo el espacio, caja que tenía que sortear para salir a flote. Los nombres, no solo de la gente sino de las cosas, le eludían, se ocultaban cerca, a la izquierda y a la derecha, como pájaros, y desaparecían rápidamente cuando giraba la cabeza hacia ellos» (Murdoch, 2006: 390).

26 Trad. de la la autora del artículo: «No tengo un mundo».

27 El pensamiento o meditación en la muerte.

28 Trad.: «En algún lugar completamente diferente, estaba el pasado, claro, coloreado, extendiéndose muy cerca de él en alguna dimensión distinta. Veía imágenes en movimiento, como películas. No era exactamente recordar» (Murdoch, 2006: 391). 
(Murdoch, 1976: 300).Y sentimos su angustia en las últimas palabras de Bruno, cuando al preguntarle el porqué de sus lágrimas responde: «I can't remember, I can't remember» ${ }^{29}$ (Murdoch, 1976: 304).

También en su magistral obra The Sea The Sea, escrita cuando la autora tenía 59 años, se explora el tema de la memoria a través de Charles Arrowby, el protagonista y voz narrativa en la obra, que invierte la primera parte del libro que denomina «prehistoria» destacando su valor. Arrowby se ha retirado voluntariamente de su vida mundana con el único propósito de escribir sus memorias, algo que perdure. A través de la narrativa personal y entrelazando el yo actual con el yo pasado reconstruye su propia identidad, recurriendo a la escritura como arma contra el olvido: «What I wrote before was written in water and deliberately so. This is for permanence, something which cannot help hoping to endure ${ }^{30}$ (Murdoch, 1980a: 2). Sin embargo, acabará combinando dos tipos de textos, memorias y diario, alternando acontecimientos presentes con recuerdos pasados con el fin de capturar el sentido del tiempo vivido.

El tema del recuerdo perdurable es una constante en la vida de Charles Arrowby. Dos fuerzas convergen al mismo tiempo: percibimos a través de comentarios de sus amigos cómo los círculos artísticos de Londres, de los que formaba parte cuando era un famoso actor y director de teatro, lo están olvidando y su popularidad se desvanece. Sin embargo, a él parece no preocuparle caer en el olvido ajeno, y lo que siente es una preocupación constante por atrapar sus recuerdos que van y vienen y que, como él dice, están escritos en agua. La novela es una continua evocación de sus recuerdos, tratando de reconstruir el pasado: «What have I got now but my memories? $\gg^{31}$ (Murdoch, 1980a: 496). En un momento dado, Charles volverá a su antigua casa de Londres con el propósito de buscar los recuerdos que ahí atesora, lo que la socióloga Violette Morin (Hockey and James, 2003: 206) denomina objetos biográficos y que han quedado atrapados e inmóviles en las fotografías de su infancia. Estos momentos capturados por la cámara son fragmentos de memoria que sobreviven y recuerdan el paso del tiempo, proporcionando una ilusión de continuidad entre el entonces y el ahora.

29 Trad.: «No puedo recordar, no puedo recordar» (Murdoch, 2006: 397).

30 Trad.: «Lo que escribí antes lo escribí en agua y deliberadamente pero esto es para que permanezca, algo que no puede renunciar a la esperanza de perdurar» (Murdoch, 1980a: 9).

31 Trad.: «¿Qué tengo yo a no ser mis recuerdos?» (Murdoch, 1980a: 390). 
En The Sea, The Sea volvemos a encontrar la imagen de la mente como un lugar oscuro que ya vimos en Bruno's Dream, las tinieblas del olvido en las que Iris Murdoch vivió sus últimos años. Ella misma empleó esta metáfora para describir su experiencia emocional frente al Alzheimer como «being in a very, very bad quiet place, a dark place ${ }^{32}$. Rememorando la alegoría de Platón, a quien tanto estudió Iris Murdoch en su faceta como filósofa, la mente de Charles deambula a través de la oscuridad de la caverna en busca de una luz que ilumine sus recuerdos. De vez en cuando aparecen destellos lejanos que le ayudan a traer recuerdos a la memoria: «wandering in my cavern, I have in fact come near to the great lightsource ${ }^{33}$ (Murdoch 1980: 77). También John Bayley (1999a: 216) concluye que cuando Iris Murdoch ya se encontraba en una fase avanzada de su enfermedad, pudo percibir algún destello en medio de su oscuridad, como cuando inesperadamente expresaba frases poéticas cargadas de significado, como si estas palabras siguieran almacenadas en algún lugar. Nos sorprende la lucidez de Murdoch cuando, en 1997, encontrándose ya en un estado avanzado de su enfermedad y consciente de ella, describe a Peter Conradi su estado a través de una metáfora un tanto compleja: «sailing away into the darkness ${ }^{34}$. De acuerdo con Ryan, Bannister y Anas (2009: 151) no es infrecuente que las personas con demencia hagan uso de metáforas elaboradas para expresarse.

Cuando Charles Arrowby en The Sea, The Sea trata de recrear su idílica historia de amor junto a Hartley (su amor de juventud), vuelve a reflexionar sobre la memoria y volvemos a encontrar la oscuridad: «How strange memory is. Since I wrote, so many more pictures of her, stored up in the dense darkness of my mind, have become available» ${ }^{35}$ (Murdoch, 1980a: 87). En el caso de Charles afortunadamente las imágenes logran salir a la luz mientras que en la mente de Bruno y de la propia Iris Murdoch la caja negra lo ocuparía todo haciendo que inevitablemente desparecieran.

El agua es una imagen recurrente en la obra de Iris Murdoch. Ella misma fue siempre una gran nadadora; de hecho, su primer recuerdo lo sitúa en el mar, bañándose con su padre. Por eso utiliza la metáfora de la mente

32 Trad. de la autora del artículo: «estar en un lugar muy muy malo y silencioso, un lugar oscuro».

33 Trad.: «Mientras vagaba por mi caverna, me he acercado en realidad a la gran fuente de luz» (Murdoch, 1980a: 102).

34 Trad. de la autora del artículo: «Navegando en la oscuridad».

35 Trad.: «Qué extraña es la memoria. Desde que lo escribí, son muchas las imágenes de Hartley almacenadas en la densa oscuridad de mi mente que han emergido a la superficie» (Murdoch, 1980a: 115). 
como lugar en el que emergen y se sumergen los recuerdos y donde algunos se hunden para nunca volver a la superficie del agua, como ocurre en The Sea, The Sea cuando Charles comenta cómo los recuerdos afloran de la oscuridad: «I could feel all sorts of dark debris from the far past shifting and beginning to move up towards the surface ${ }^{36}$ (Murdoch, 1980a: 131).

La preocupación por la pérdida de la memoria vuelve a aparecer tras el incidente en el que alguien arroja a Charles a un pozo y milagrosamente logra sobrevivir. Ya en su casa, Charles recuerda un detalle importante de lo ocurrido y le urge escribirlo para evitar que ese repentino recuerdo se sumerja en la oscuridad, ya que a consecuencia de la caída va a sufrir una amnesia transitoria. La escritura es el flotador de la memoria, la evidencia de algo que ya empieza a olvidar mientras escribe: «I had to record this important thing, to catch it and hold it before it disappeared ${ }^{37}$ (Murdoch, 1980a: 367), como si el olvido fuera un ser traicionero que en cualquier momento pudiera apropiarse de sus recuerdos y llenarlo todo con el negro olvido. Esta angustia se hace más real cuando el médico que le visita, tras sufrir la conmoción por la caída al agua, le indica que quizá no recuerde cosas que hayan sucedido antes o después de su caída. De ahí, su obsesivo esfuerzo por recuperar algo que ha olvidado y que con el tiempo lograría. El pozo donde ha caído a traición es un lugar oscuro, como el olvido. Pero Charles sobrevive a la caída y sobrevive al olvido, se recupera físicamente y recuerda al cabo del tiempo los detalles de lo ocurrido, tal como el doctor le advirtió. Volverá Charles a referirse a esta caverna submarina al recordar una conversación mantenida con su amante Clement: «dredged up out of the deep sea caves of memory ${ }^{38}$ (Murdoch, 1980a: 428). Así, pues, la imagen de las tinieblas de la memoria y de su afán por sacar a flote los recuerdos es recurrente en la obra de Iris Murdoch. Como ella misma expresó, por boca de Charles Arrowby, sus recuerdos no lograron salir a la superficie y se hundieron para siempre en la profundidad de su memoria: «I had a terrified sense that if I did not catch it now it would disappear

36 Trad.: «Noté que numerosos y vagos desechos de un remoto pasado se soltaban y empezaban a ascender a la superficie» (Murdoch, 1980a: 168).

37 Trad.: «Tenía que tomar nota de eso tan importante, atraparlo y retenerlo antes de que desapareciera» (Murdoch, 1980a: 478).

38 Trad.: «desenterrada de las profundas cavernas submarinas de la memoria» (Murdoch, 1980a: $559)$. 
forever, sinking into the deep total darkness of the unconscious» ${ }^{39}$ (Murdoch, 1980a: 467).

Nos quedamos con la última reflexión de Charles, cuando al final de la novela da un giro y se adentra en un terreno pantanoso. Pese a la importancia de la memoria en la construcción de la identidad de la persona que ha indicado desde el comienzo de la narración, ahora se da cuenta de la imposibilidad de recordar, advirtiendo al lector de la inestabilidad de la memoria y de su poca fiabilidad en contra de lo que él pensaba: «That we cannot remember such things, that our memory, which is our self, is tiny, limited and fallible, is also one of those important things about us, like our inwardness and our reason» (Murdoch, 1980a: 492) ${ }^{40}$.

La obsesión por la pérdida de la memoria que muestra Iris Murdoch en las obras anteriores a su diagnóstico podría tratarse de un miedo existencial relacionado con su faceta como filósofa, pero también podría deberse a la huella que dejó en ella el cuidado y observación de la demencia de su madre que tan de cerca vivió, así como su muerte cuando la escritora tenía sesenta y seis años. Pero también lleva al lector a sospechar si esta preocupación por la memoria podría ser secundaria a un deterioro cognitivo leve, del cual ella pudiera haber sido consciente y que pudo aparecer en una fase preclínica, décadas antes del diagnóstico de la enfermedad.

John Bayley, principal testigo de la última etapa de la escritora, escribió sobre sus últimos momentos junto a Iris Murdoch: «we are physically closer [...] She is not sailing into the dark. The voyage is over, and under the dark escort of Alzheimer's, she has arrived somewhere. So have I» (1999a: $183)^{41}$. Su obra quedará siempre plasmada en sus libros, y de esta manera, aunque ella olvidara que un día fue escritora y escribió libros, sus lectores no la olvidaremos.

39 Trad.: «tenía la aterrorizada sensación de que si no conseguía atraparlo en aquel momento desaparecería para siempre, hundiéndose en la profunda oscuridad, total, del inconsciente» (Murdoch, 1980a: 611).

40 Trad.: «que no podamos recordar esas cosas, que nuestra memoria, que somos nosotros mismos, sea diminuta, limitada y falible es también una de esas cosas que son importantes en nosotros, como nuestra capacidad de interiorización y nuestra razón» (Murdoch, 1980a: 640).

41 Trad.: «Cada día estamos físicamente más cerca [...] Iris no navega en la oscuridad: el viaje ha concluido, y con la oscura escolta del Alzheimer, Iris ha llegado a alguna parte. Yo también» (Bayley, 1999b: 221). 


\section{REFERENCIAS BIBLIOGRÁFICAS}

ALGADO, M.T.; BASTERRA, A. y GARRIGÓS, J.I. (1996). «Envejecimiento y enfermedad de Alzheimer». Revista Española de Investigaciones Sociológicas (REIS). Monográfico sobre «Sociología de la Vejez» coord. por M.T. Bazo, 73, 81-104.

BAYLEY, John (1999a). Elegy for Iris. New York: St. Martin's Press.

- (1999b). Elegía a Iris. Trad. Fernando Borrajo. Madrid: Alianza Editorial.

BYATT, A. S. (2005). Little Black Book of Stories. New York: Vintage International.

CANTOS GÓMEZ, P. (2010). «Analyzing the Oral Speech of an Alzheimer Affected Person: A Case Study». Statistical Analysis. Proceedings of 10th International Conference on Statistical Analysis of Textual Data 2.

CARRERA, I.; ETCHEVERRÍA I.; FERNÁNDEZ-NOVOA, L.; LOMBARDI, V.; CACABELOS, R. y VIGO, C. (2012). Vaccine Development to Treat Alzheimer's disease Neuropathology in APP/PS1 Transgenic Mice, vol. 2012, article ID 376138, 17 pages.

CONRADI, P. (2010). Iris Murdoch: A Life. London: HarperCollins.

DIPPLE, E. (1982). Iris Murdoch, Work for the Spirit. London: Methuen.

DOMÍNGUEZ SÁNCHEZ, J. (2004). «El deterioro cognitivo en la enfermedad de Alzheimer». Jano: Medicina y Humanidades, vol. 67, 1530, 59.

EYRE, R. (ed.). (2002). Iris [DVD]. Barcelona: Manga Films.

FRIEDAN, B. (1994). La fuente de la edad. Barcelona: Planeta.

GARCÍA MÁRQUEZ, G. (1984). Cien años de soledad. 7. a ed. Madrid: Espasa-Calpe, Selecciones Austral.

GARRARD, P.; MALONEY, L. M.; HODGES, J. R. y PATTERSON, K. (2005). "The Effects of Very Early Alzheimer's Disease on the Characteristics of Writing by a Renowned Author». Brain 128 (2), 250-260.

HOCKEY, J.L. y JAMES, A. (2003). Social Identities across the Life Course. Basingstoke: Palgrave.

KONTOS, P. C. (2003). «The Painterly Hand»: Embodied Consciousness and Alzheimer's Disease. Journal of Aging Studies 17 (2), 151-170.

LANCASHIRE, I. y HIRST G. (2009). «Vocabulary Changes in Agatha Christie's Mysteries as an Indication of Dementia: A Case Study». Ed. 19th Annual Rotman Research Institute Conference, Cognitive Aging: Research and Practice. Toronto. 
LEITH, S. (2009, abril 25). «Writing in terms of pleasure». The Guardian.

MARTÍNEZ LAGE, J. M. y MARTÍNEZ-LAGE, P. (2001). «Educación, reserva cerebral y factores de riesgo de demencia y enfermedad de Alzheimer». Medicina Clínica 116.11, 418-21.

MCCOLGAN, G.; VALENTINE, J. y DOWNS, M. (2000). «Concluding Narratives of a Career with Dementia: Accounts of Iris Murdoch at her Death». Ageing \& Society, 20 (01), 97.

MIRANDA C. M.; PÉREZ J. C. y SLACHEVSKY, Ch. A. (2011). «Jonathan Swift y su contribución científica en Los viajes de Gulliver». Revista Médica de Chile 139 (3), 395-399.

MURDOCH, I. (1974). The Sacred and Profane Love Machine. London: Chatto \& Windus.

- (1976). Bruno's Dream. Harmondsworth: Penguin Books.

- (1980a). The Sea the Sea. Penguin Books.

- (1980b). La máquina del amor sagrado y profano. Barcelona: Ediciones Destino.

- (2003). The Black Prince. New York: Penguin Books.

- (2004). El mar, el mar. Trad. Miguel Temprano. Barcelona: Lumen.

- (2006). El sueño de Bruno. Trad. Ángela Pérez y José María Álvarez. Barcelona: Lumen.

- (2009). El príncipe negro. Traducción de Camila Batlles. Barcelona: Debolsillo.

MURDOCH, I. y DOOLEY, G. (2003). From a Tiny Corner in the House of Fiction: Conversations with Iris Murdoch. Columbia, S.C.: University of South Carolina Press.

QIU, C.; BÄCKMAN, L.; WINBLAD, B.; AGÜERO-TORRES, H. y FRATIGLIONI, L. (2001). «The influence of education on clinically diagnosed dementia incidence and mortality data from the kungsholmen project». Archives of Neurology, 58 (12), 2034-2039.

RASCOVSKY, K.; GROWDON, M. E.; PARDO, I. R.; GROSSMAN, S. y MILLER, B. L. (2009). "'The quicksand of forgetfulness': semantic dementia in One hundred years of solitude». Brain: A Journal of Neurology 132, 2609-2616.

RSNA (2012). «Researchers Discover Gender-based Differences in Alzheimer's Disease». Radiology Society of North America Annual Meeting. Comunicado de prensa, 26 noviembre. http://www2.rsna.org/ timssnet/Media/pressreleases/pr_target.cfm?id=634. 
RYAN, E. B.; BANNISTER, K. A. y ANAS, A. P. (2009). «The dementia narrative: Writing to reclaim social identity». Journal of Aging Studies 23 (3), 145-157.

SWEETING, H. y GILHOOLY, M. (1997). «Dementia and the phenomenon of social death». Sociology of Health \& Illness 19 (1), 93-117.

SWIFT, J. (1992). Gulliver's Travels. Wordsworth Editions Limited.

- (1987). Los viajes de Gulliver. Madrid: Alianza.

TODD, R. (1984). Iris Murdoch. London: Methuen. Contemporary Writers.

WORLD HEALTH ORGANIZATION (2011). Global Health and Aging. National Institutes of Health (NIH). Publication n. ${ }^{\circ}$ 11-7737 (También en http: //www.who.int/ageing/publications/global_health.pdf).

WORLD HEALTH ORGANIZATION AND ALZHEIMER'S DISEASE INTERNATIONAL (2012). Dementia: A Public Health Priority. Geneva; London: World Health Organization; Alzheimer's Disease International.

ZAMBRANO CRUZ, R. y CEBALLOS CARDONA, P. (2007). «Síndrome de carga del cuidador». Revista Colombiana de Psiquiatría 36, 26-39.

Recibido el 30 de mayo de 2013.

Aceptado el 19 de septiembre de 2013. 